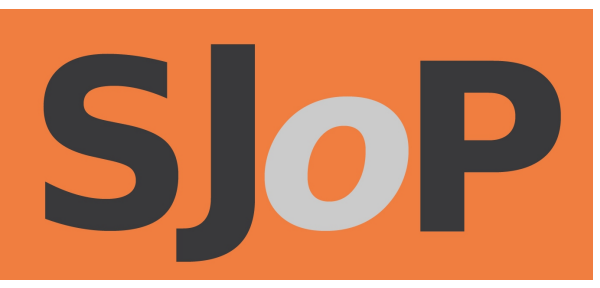

Dislocation and relocation: clarsach and live electronics

ALISTAIR MACDONALD

The Scottish Journal of Performance

Volume 2, Issue 1; December 2014

ISSN: 2054-1953 (Print) / ISSN: 2054-1961 (Online)

Publication details: http://www.scottishjournalofperformance.org

To cite this article: MacDonald, A., 2014. Dislocation and relocation:

clarsach and live electronics. Scottish Journal of Performance, 2(1), pp.1128.

To link to this article: http://dx.doi.org/10.14439/sjop.2014.0201.02

This work is licensed under a Creative Commons
Attribution 4.0 International License. See
http://creativecommons.org/licenses/by/4.0/ for details. 


\title{
Dislocation and relocation: clarsach and live electronics
}

\author{
ALISTAIR MACDONALD
}

DOI: 10.14439/sjop.2014.0201.02

Publication date: 16 December 2014

In writing The Salutation (clarsach and electroacoustic sound) for harpist Catriona McKay in 2002, I wanted to create something which celebrated the history and music of the instrument itself, using studio technology to create a bridge between idiomatic writing for the instrument and environmental/anecdotal sound, including the voice, which referenced place and time.

This paper will chart and reflect on the collaborative work we have done together since then, describing our methodology for interrogating and relocating the clarsach. It will explore how we consciously play with musical, sonic and conceptual distances in our improvised performances, and examine aspects of this shared 'performance ecosystem' (Waters, 2007), which enables us to function in multiple contexts.

Keywords: clarsach, live electronics, improvisation

[T]he constraints and constructs upon which music depends are not only, not even mostly found in the physical object of the instrument, but also in the physiology of this particular body, in the assumptions and embodied knowledge which operate in this particular player and in the interpenetrations between all of these and the framing acoustic and social environment (Waters, 2007, p.3). 
In 2002, I was commissioned by harpist Catriona McKay to write The Salutation, a piece for clarsach and electroacoustic sound. Following this, we began to work on projects combining improvisation with live electronics, rather than creating fixed, pre-recorded electroacoustic parts. Some of this work, especially the ensemble projects, has clear connections to Scottish traditional music, principally through a preponderance of melodic material. Alongside this, the work of our duo, Strange Rainbow, is much more connected to our experiences in other genres and contexts, often exploring sound for its own sake. I hope to show how through this work we have developed a practice based on 'scales of dislocation' that relocates the clarsach and allows our music to function in multiple musical contexts.

Simon Emmerson (2012) discusses 'location' of live electronic music and considers the 'relocation of the live' (p.8) that technology brings about. He explores the nature of liveness of performance in space, time and causality, and suggests the idea of 'meaningful response' as a way to measure the effectiveness of interactivity. He says:

A performer might ask 'where are we?' in reference to a printed score or given structure within the (perhaps unwritten) music; but this question can also be asked with respect to a venue, furthermore we can ask it about a historical or sociological 'position'. It seems that this question is the most comprehensive it is possible to ask! (Emmerson, 2012, p.8)

In this paper I want to look at how the practice I have developed with Catriona McKay has allowed us to relocate the clarsach, a particularly Scottish instrument, in relation to its traditional identity and in different musical contexts, and how we have developed an interactive environment that facilitates 'meaningful response'. 
In composing The Salutation I wanted to find a way of locating the clarsach in a consciously Scottish frame and to draw, as far as possible, on the instrument's Scottish identity within the bounds of my own musical language, which is rooted in contemporary classical, electroacoustic music. The reason for doing so was that, although the commission was for an electroacoustic piece, Catriona wanted music that she could perform in a programme of traditional Scottish music, rather than something intended for a concert of contemporary classical music. While I had composed for instruments and 'tape' or live electronics in the past, I had always avoided bringing extra-musical references (recognisably real-world, non-instrumental sounds or references to other musics) into these works, so this was a significant challenge for me. Throughout the process I was concerned not to lose sight of the clarsach: its characteristic sound, the physical and mechanical constraints of instrument and performer and the 'baggage' it brings with it as an instrument of folk history and culture. At the back of my mind were both my reading around that time of Hugh Trevor-Roper's (albeit exaggerated) portrayal of 'Scottishness' as a nineteenth century constructed mythology (Hobsbawm and Ranger, 1983), and an awareness of my own family's constructed Scottish mythology (one completely invented by my grandfather that prompted my parents to give me my Scottish first name, and that we only discovered to be fictitious years after his death). I therefore approached the task of composing something intended to be consciously 'Scottish', for a specifically Scottish audience, with some caution, avoiding musical pastiche and trying to incorporate signifiers of cultural identity. These would include sounds of the instrument, of place, of speech and other recognisable sounds referenced in the spoken words.

The clarsach is the Scottish member of the Celtic harp family. The earliest known examples date back over a thousand years and, along with the Great Highland Pipes, it 
was an instrument of high status in the courts of clan chiefs up until the eighteenth century and so holds an important place in Scottish cultural history. Keith Sanger and Alison Kinnaird (1992) provide a detailed history of the instrument devoted largely to the period from the earliest records to its decline, which ran in parallel with that of Gaelic culture and patronage in the eighteenth century. Their invaluable work in rediscovering ancient repertoire laid the foundation for the revival of the instrument and its music over the past 40 years. Now a very familiar instrument in contemporary Scottish traditional music, its repertoire comprises music from the past along with a large body of work composed by contemporary players. This largely sits within and around the generic forms associated with Scottish traditional music, particularly dance forms such as reel, jig, strathspey and waltz, along with airs and other slower music. In addition, as contemporary Scottish traditional musicians absorb, at an ever increasing rate, influences from many other traditions and genres, the clarsach music we hear is ancient, modern, Scottish and global in origin. Nevertheless, the sound of the instrument (notwithstanding the differences between ancient and modern instruments, which also continue to evolve) is associated with a broadly Celtic identity, and certainly within scotland an audience for Scottish traditional music would consciously ascribe 'Scottishness' to it in the same way as it might to the Great Highland Pipes.

In previous electroacoustic works without instruments I had made reference to place. These include Busk (with Nicholas Virgo, 1988), based on the sounds of street musicians in Birmingham, Final Times (1998), an audio portrait of Glasgow, and Bound for Glory (2002), set in southern Poland. There are also two works for dance, Making of Maps (1992) and So Many Islands (1996), which more generally reference city and coastline, respectively. So, I decided to use sounds of place to help situate the music of The Salutation. I chose to begin with a recording I had made of Margaret Hughes, a 90-year-old woman from 
Buckie in the North East of Scotland, recalling her time as a 'fisher quine' ('quine', a Scots word for a young woman) in the 1930s herring industry in Shetland. Margaret's voice gave me a distinctive accent along with a specifically Scottish narrative which referenced a specific time in the past, a subject ('the herrin' fishin'...') and a place (Shetland Margaret talks about working in the town of Lerwick). Her words also hint at other, less specific things that allowed me to incorporate exterior, environmental sounds (the sea, gulls, fishing boats, a harbour) and the domestic setting of Margaret's reminiscences (the sound of a grandfather clock). I use only fragments of Margaret's story but these fragments are enough to situate the narrative ('I belong up North in Buckie... aye, when I was sixteen... 1939 at the guttin'... at the herrin' fishin'... you worked three o' ye... two o' ye an' a packer... three in a crew... gutted and packed... herrin' barrels... thruppence the hour... at the herrin' fishin'..., and so on). These spoken fragments were combined with the other recordings and additional recorded clarsach sounds to create the electroacoustic part. So, while the live instrument has been dislocated from its familiar musical surroundings, the combination of clarsach-based sound and recognisable, 'referential' sounds, along with melodic elements, creates a sonic context for my more fragmented, less idiomatic instrumental writing. If this works for its intended audience, as I believe it does, it relies not on knowledge of electroacoustic repertoire but rather on a shared experience of sound design in film and television (which, of course, can also be an important point of reference for the expert audience).

The process of composing the clarsach part for The Salutation was collaborative and to some extent improvisatory. In writing the score, I worked closely with Catriona to unpick some of the instrument's and specifically her characteristics, idiomatic gestures and sounds. The live clarsach part moves between texture and gesture, relating and reacting to the voice and environmental sounds. 
Catriona's love of reshaping simple arpeggios, her characteristic rhythmic driving chords and intricate high, repeated, improvised patterns all find their way into the writing. At the opening, for example, as the regular ticking of a clock gradually morphs into the arrhythmic clicking of rigging on ships' masts, simple repeated notes are gradually subsumed into more complex irregular note textures. Interjections of speaking voice are mirrored by broken clusters of notes which themselves suggest fragments of an imagined or half-remembered melody. Later in the piece, melodic writing is woven in, emerging from pitched, electroacoustic textures and rapid, repeated (diatonic) clusters, and gradually becoming fragmented in both register and meter as extra-musical sounds return.

The Salutation was to become the first step in a lasting collaboration to which we have both brought a range of musical experience. As improvisation was already part of our own practices, and as this had been part of the compositional process, it became our environment and methodology for further exploration. My own practice as a composer in the electroacoustic studio has always acknowledged the performative, improvisational and playful opportunities that the studio affords. Alongside this I had also had the opportunity to work with some extraordinary improvisers from the world of free jazz (including Paul Dunmall, 1997-2001, and Keith Tippett, 1999), I had improvised with dancers/choreographers (including Sue MacLennan \& Company, 1993, and Anna Krzystek, 2000-2002) and I was soon to make large-scale, performative and improvisatory interactive installations (Sensuous Geographies with Sarah Rubidge, 2002-2003; Sea Unsea with Carol Brown and Mette Ramsgard Thomsen, 2005-2006). I also brought experience of writing fixed electroacoustic pieces as well as works with instruments and voices, and I had much experience performing electroacoustic work by other composers (working with Sonic Arts Network, 1985-2002, and Birmingham 
Electroacoustic Sound Theatre, 1985-1995). Though Catriona is known principally as a clarsach player, as a soloist and in other contexts, she also plays organ and pedal harp. Improvisation has been part of her musical practice throughout her career and she is a member of the Glasgow Improvisers' Orchestra and other improvising groups. She is a prolific composer, largely of new traditional music, and is in demand as a player of contemporary harp music.

Throughout our work together since The Salutation we have continued to develop our sonic resources. For Catriona, improvisation has always been a place to explore different ways of playing the clarsach. For example, she uses plectra, guitar steels, and less conventional objects such as knitting needles and battery-powered fans, to prepare (in the sense of John Cage's prepared piano) or excite the strings. She also draws on harp techniques from other cultures, for example, that of playing hard, damped glissandi, which is something she found listening to Patagonian harp playing. I have continued to collect sounds of place and other 'realworld' reference. At the same time, I developed (and continue to refine) a collection of software tools and control interface mapping to capture, trigger and process sounds, working with MIDI controllers, sensors, pedals and touchscreen interfaces to achieve the fluid and rapid, performative control of sounds and their transformation.

The work that followed The Salutation can be divided into two distinct strands. The ensemble projects I shall describe have a musical core close to Catriona's Scottish traditional music yet also extend that language in ways that Lori Watson describes as 'beyond-tune'.

By 'beyond-tune', I refer to a piece of music that is longer in length and/or significantly more complex in arrangement, in terms of the textures created by utilising instrumentation, extended performance techniques and harmony, than, as 
an example, a 'set' of three reels each consisting of 32 bars of melody with chord accompaniment... (Watson, 2013, p.38)

In her research, Watson makes a very useful survey of innovation and innovators in traditional music in Scotland, especially over the last thirty years (including Catriona's work, Floe). This is perhaps the most appropriate 'lens' through which to understand this strand of our work.

This move towards more complex forms and the adoption of new harmonic, melodic and rhythmic material is a significant trend in Scottish traditional music. As Simon McKerrell (2014) notes:

What was once considered kitsch tartanry has been re-mythologized and now hybrid sounds from Scottish musicians portray a newer, emergent sense of national identity. Increasingly, musicians are performing deterritorialized and commodified music which is shifting attention away from musical provenance and authentic ideology towards more transient sonic identities and blurring established musical genres (N.P.).

Our first piece after The Salutation which consciously ventured 'beyond-tune' was Mareel in 2007. Alongside mixing the recording of Catriona's CD Starfish (clarsach with string ensemble) we reworked the opening track, improvising with live electronics to create Mareel, which became the final track on the CD. Catriona's music for clarsach and string ensemble on this disc sits firmly in the genre of New Traditional music (Watson, 2012). In Mareel, the melodic materials from Starfish are clearly present and recognisable, but are also transformed with unconventional harp techniques, improvisation and live electronic processing. As pulse and harmony dissolve into texture, the structure departs from something defined by regular 
groupings of bars and chords to become distinctly 'beyondtune'.

Following the critical success of this CD, Catriona was commissioned by Celtic Connections (Glasgow's annual world music festival) to create Floe in 2008, a large-scale work for fiddle, accordion, piano, nyckelharpa, clarsach and live electronics. Floe was first performed at Glasgow Royal Concert Hall then toured smaller traditional music venues across Scotland. The piece draws influence from Catriona's previous collaborations with each of the musicians, and their different musical references find their way into Catriona's own distinctive language. In this case, live electronics are present through much of the work and there are also substantial sections with live electronics that involve the whole group improvising.

Later in 2008, Catriona and I were invited to the Norwegian Film Festival and commissioned to compose new music for a Norwegian silent film, Historien om en gut (1919). This is scored for clarsach, strings and electronics, and, again, consists of composed and improvised elements based around tonal, melodic 'traditional' writing. More recently, we worked with Gaelic singer Margaret Bennett on Ciodabhaig, based around a 1940s film, The Western Isles, and the Scottish Gaelic singer Kitty MacLeod, who appears in the film.

As Strange Rainbow, our improvised duo performances have been very different from these composed projects, involving little or no diatonic, harmonic or melodic material. For us this has been an outlet for a very different kind of music, in which we seek a new voice for the clarsach without reference to its Scottish identity. This body of work, which is usually performed for very diverse audiences and draws more heavily on other facets of our musical experiences in different genres, demands a quite different 
contextualisation.

Unlike Floe, Strange Rainbow performances have taken place in venues not generally associated with traditional music, and for promoters of non-traditional arts and music. They have included a night club setting in Manchester as part of a sound art festival (Sonic Arts Network Expo Festival 2006); 'Noisy Nights' at the Traverse Theatre, Edinburgh, and 'What Happened' at The Arches (an underground contemporary performance venue in Glasgow) for contemporary music ensemble Red Note; Glasgow Improvisers Orchestra's GIO Festival 2008, at Glasgow's Centre for Contemporary Arts; and 'Fest'n'Furious' at Dundee Contemporary Arts, 2007. We have played to an audience for traditional music once, at Celtic Connections' A Night of Celtronika (2011) at 2am in The Old Fruitmarket, Glasgow in the same programme as a string ensemble, rock bands, 'Punjabi-electronica pop-art' and more. As Waters says, 'the constraints and constructs upon which music depends [relate to] the framing acoustic and social environment' (2007, p.3). Venue, location, promoter and other musicians sharing the bill all not only colour an audience's expectation, but also influence our musical approach to an improvised performance.

Examples of this side of our output can be heard on our two CDs of improvised music, invisible from land and sea (2008) and skimmerin' (2009). In both cases, the music, or certainly our intention for it, was located more comfortably within a practice of free improvisation than 'beyond' anything.

invisible from land and sea (2008) is 'located' in the studio, recorded over a number of intense sessions with no audience. The sound world is close, dry and intense. The clarsach sounds are far from the conventional, plucked notes of the traditional instrument. Hand-held fans buzzing 
against the strings create mechanical, often distorted textures, or clicks and scrapes are captured and looped. The harp becomes part of a single-sounding texture that is often indistinguishable from its electronic other.

skimmerin' (2009) was a live recording of outdoor performances in the ancient Battlehill Woods in Aberdeenshire. It was the culmination of an extended residency exploring the area, listening to and recording local rivers, wind turbines, voices, forest birds, distant farm machinery, amongst other things. The performance incorporates and responds to the environmental sounds of that location, though not its cultural history or the clarsach's place in it. Here, the harp is often more clearly distinguishable, weaving in and out of the electroacoustic soundscape, but still located within a sound world rooted in free improvisation.

Given our experience in multiple musical genres it is perhaps interesting to consider how audiences hear, locate and construct meaning in our music. Beyond the broad labels of 'free improvisation' and 'beyond-tune', where might one locate this body of work? Some audiences hear our performance in relation to the broad genre of works for instruments and 'tape' or instruments and electronics. My own practice as composer, my experience as performer/sound engineer with Birmingham Electroacoustic Sound Theatre and Catriona's performances of contemporary classical music might well suggest it. Others hear it in relation to their experience of free improvisation, in which live electronics has a long history. Groups such as AMM and Gentle Fire in the 1960s and 1970s were pioneers, and Evan Parker's Electroacoustic Ensemble is prominent today. Parallels might also be drawn with other work that seeks to explore traditional musics with improvised live electronics, including, for example, Yannis Kyriakides's work (2006) with guitarist Andy Moor, 
which explores the Greek tradition of rebetika. There are other examples of music exploring traditional harps and electronics, such as Ruth Wall's long-standing duo (lever harp, Bray harp, wire strung harp) with Graham Fitkin, and Şirin Pancaroğlu's recent collaboration on traditional Turkish harp with Erdem Helvacioğlu's live electronics (2010).

Our most recent project draws the two strands of our practice back together with a return to melodic and harmonic materials as the source for improvisation. A more ambitious project than Mareel, it is a reworking of all of the material on Catriona's most recent acoustic CD Harponium (clarsach and harmonium) with live electronics in place of harmonium. It draws on the ideas, materials and structures in improvised reimaginings. This work 'remembers' fragments of Catriona's acoustic music and consciously recalls the stereotypical 'clarsach'. Recognisable elements characteristic of Catriona's new traditional writing are present in idiomatic instrumental gestures, references to traditional forms, rhythms and harmony/modality. Unlike The Salutation, though, these are unfixed, improvisatory reworkings that change substantially from one performance to the next. In this excerpt, a rhythmic figure from the original is sampled and looped, forming a pulsebased backbone for our playing. The movement in and out of pulse, in and out of harmony and mode is where we find the connection with our freer improvisation.

Reflecting on the musical and technical processes we employ, it is clear that over a number of years we have developed strategies that allow us to function in multiple musical contexts while maintaining an identifiable core practice. This might best be described as playing with scales of dislocation on a number of levels. Though these strategies and processes are not important to the listener (as Emmerson (2013) says, we hear effects, not causes), they 
are nonetheless the underlying strategies that allow us to generate 'meaningful response' in our performance. As I have already suggested, we interrogate the distance between traditional and free improvised music, between an apparently familiar world and a new one, albeit one which has its own language and codes. The work may also be perceived to lie somewhere along other lines between genres- between 'contemporary music for instrument and electronics' and 'noise music'. We also locate the clarsach somewhere along a continuum from sound worlds which are familiar or real (musically or environmentally speaking), via those which might appear surreal (strange, uncanny, not quite believable), to somewhere apparently alien. On a simple technical level, we explore distances between direct and more processed sounds. Denis Smalley describes source bonding as 'the natural tendency to relate sounds to supposed sources and causes, and to relate sounds to each other because they appear to have shared or associated origins' (1997, p.110). A live instrument is naturally, highly source-bonded: we see the player and their physical gestures, and the nature of the sounds we hear is expected so we assign the instrument as the source of the sound. Some of Catriona's playing techniques and preparations (plating with plectra, damping the strings with found objects, and inserting foam, wooden skewers and wire between the strings) already alter the clarsach's timbre and make it less recognisable. Yet Emmerson (1998, p.148) points out that in live electroacoustic works 'the instrument is the anchor... We always refer back to its presence... Including an extended instrument'. Some of the electronic processes simply create repetitions of the live sound ('first order surrogacy' (Smalley, 1986, p.82)), and others transform it completely ('remote surrogacy' (ibid.)). This distance between the 'fact' of the live instrument and the mediated illusion gives us a powerful musical space in which to operate, as indeed we often do.

The use of external sounds and semi-composed materials, 
in other words, sounds not only resulting from live electronic processing, is also a feature of our performance. There is a peculiar orthodoxy in some live electronic performance that demands all sonic materials be created in the moment. However, as Emmerson (1998) points out, a range of electroacoustic materials related and unrelated to the live instrument affords a greater variety of potential musical relationships. This is something I had explored in previous work for instruments and 'tape'. I often recontextualise the instrument with sounds from the (apparently) real to the surreal, along what John Young (1996, p.83) calls the 'reality-abstraction continuum'. In The Salutation, the illusory context was thematic. In other performances we play with changing realities, exploring the tensions in the references these sounds carry; the reframing of a musical figure changes its meaning, and, of course, there are parallels with common musical practices such as the reharmonisation of a melody. The processing of sampled harp sounds can also be heard in this way - the 'real' harp becomes surreal, or loses its sonic identity completely and becomes 'abstract'. For us, the use of 'external' material dislocated in time and place is a crucial part of the relocation of the harp and it also gives me, the live electronic performer, the opportunity to go beyond a reactive role, to interact and provoke. I can more easily (playfully) surprise Catriona and it gives us the opportunity to work with a greater degree of polyphony and heterophony in performance.

The live electronic processes we use have gradually coalesced into an adaptable toolkit that allows us to articulate various 'distances' with great flexibility. Microphones on the harp are fed into my computer; sounds from the microphones both unaffected and processed are then mixed with other sounds and output to loudspeakers. The processes are relatively straightforward in themselves but I have built varying levels and scales of unpredictability into the parameters to allow for a greater degree of play. 
They can be described in terms of how they affect time, texture, space and timbre.

Delays (or 'echoes') spread out from Catriona at centre stage, reinforcing the temporal de-centring and scattering in their spatial behaviour; they can accelerate, decelerate, become successively louder or die away. Other delays have resonant filters which sweep dynamically; variable unpredictability can be applied to spatial position and spatial trajectory as well as to equalisation and resonance.

Granulation (temporal fragmentation of a stream of sound) similarly spreads the instrument's sound spatially and temporally with variable degrees of randomness; these processes can be controlled to create swarms or trails of sound fragments that recede into the distance, or dense clusters of fragments that mask the live clarsach. This can disturb or interrupt the flow of time in the instrumental performance.

Other processes create continuous textures from the sound of the clarsach, ranging from smooth drones to motoric, pulse-based layers or chaotic webs. Loops (repeated, short recorded fragments) and layers of loops can be subject to controlled or random dynamic change. They can be filtered and spatialised to appear distant (behind the live instrument), to appear to float above or to cut across the spectral frame, or they may drift within the stereo image. The fragments themselves can be stable and mechanically repetitive, or the looped selection can shuffle, constantly desynchronising. Thus, we can play between pulse-based and pulse-less textures.

Simon Waters' writing about performance ecosystems (2007 and 2013) has a very powerful resonance for me. Indeed, Catriona sometimes describes me (along with my laptop) as 
part of her harp, though this might be better described as our performance ecosystem. It enables dynamic exploration of different clarsachs, different histories and different physicalities. From subtle shifts to radical, chaotic reshaping, 'electroacoustic dislocation' provides a multidimensional space, which has evolved around this particular instrument and specific aspects of its musical language. Our collaborative partnership ostensibly began with an intention to relocate the clarsach as a Scottish instrument for the twenty-first century (a rather grand ambition!). Nevertheless we have developed a practice flexible enough to relocate across genres of live electroacoustic music, new 'beyond-tune' Scottish Traditional music and free improvisation.

\section{References}

Emmerson, S., 1998. Acoustic/electroacoustic: the relationship with instruments. Journal of New Music Research, 27(1-2), pp.146-164. http://dx.doi.org/10.1080/09298219808570742.

Emmerson, S., 2012. Location-dislocation-relocation (Where is live electronic music?). Proceedings of the IV Seminar-Music Science Technology: Frontiers and Ruptures, July 2012, São Paulo (Brazil), pp.7-16.

Emmerson, S., 2013. Rebalancing the discussion on interactivity. Proceedings of the Electroacoustic Music Studies Network Conference: Electroacoustic Music in the Context of Interactive Approaches and Networks, Lisbon, June 2013.

Hobsbawm, E. and Ranger, T. eds., 1983. The invention of tradition. Cambridge: Cambridge University Press.

http://dx.doi.org/10.1017/cbo9781107295636.

Kyriakides, Y., 2014. Yannis Kyriakides : rebetika. [online] Available at: 〈http://www.kyriakides.com/rebetika.html〉 [Accessed 16 October 2014]. 
MacDonald, A., 2002. The salutation. [sound recording] Performed by Catriona McKay. Unpublished.

MacDonald, A., 2014. [online] Available at:

〈http://www.alistairmacdonald.co.uk $\rangle$ [Accessed 16 October 2014].

McKay, C., 2007. Starfish. [CD] Glasgow: Glimster Records.

McKay, C., 2013. Harponium. [CD] Glasgow: Glimster Records.

McKay, C., 2014. home / CATRIONA MCKAY / Catriona McKay 2014. [online] Available at: 〈http://www.catrionamckay.com〉 [Accessed 16 October 2014].

McKerrell, S., 2014. musicalmeaning.com. [online] Available at: 〈http://www.musicalmeaning.com〉 [Accessed 16 October 2014].

Pancaroğlu, Ş. and Helvacioğlu, E., 2010. Resonating universes [CD] London: Sargasso.

Sanger, K. and Kinnaird, A., 1992. Tree of strings-Crann nan Teud; a history of the harp in Scotland. Edinburgh: Kinmor Music.

Smalley, D., 1986. Spectro-morphology and structuring processes. In Emmerson, S. (ed.) The language of electroacoustic music. London: Macmillan. pp.61-93.

Smalley, D., 1997. Spectromorphology: explaining sound-shapes. Organised Sound, 2(2), pp.107-126. http://dx.doi.org/10.1017/S1355771897009059.

Smalley, D., 1994. Defining timbre-refining timbre. Contemporary Music Review, 10(2), pp.35-48.

http://dx.doi.org/10.1080/07494469400640281.

Strange Rainbow. www.strangerainbow.co.uk [online]. Available at: 〈http://www.strangerainbow.co.uk〉 [Accessed 16 October 2014].

Strange Rainbow, 2008. invisible from land and sea. [CD] Glasgow: Mirror-image.

Strange Rainbow, 2009. skimmerin’ [CD] Glasgow: Mirror-image. 
Strange Rainbow, 2014. Harponium improvisation. [sound recording] Unpublished.

Waters, S., 2007. Performance ecosystems: ecological approaches to musical interaction. EMS-07 Proceedings (Electroacoustic Music Studies Network). [online] Available at: 〈http://www.emsnetwork.org/spip.php?article278〉 [Accessed 16 October 2014].

Waters, S., 2013. Touching at a distance: resistance, tactility, proxemics and the development of a hybrid virtual/physical performance system. Contemporary Music Review, 32(2-3), pp.119-134. http://dx.doi.org/10.1080/07494467.2013.775818.

Watson, L., 2013. The new traditional school in Scotland: innovation, beyond-tune composition and a traditional musician's creative practice. $\mathrm{PhD}$, University of St Andrews.

Young, J., 1996. Imagining the source: the interplay of realism and abstraction in electroacoustic music, Contemporary Music Review, 15(1-2), pp.73-93. http://dx.doi.org/10.1080/07494469608629690

\section{About the author}

ALISTAIR MACDONALD is a composer and performer of electroacoustic music. His work draws on a wide range of influences, reflecting a keen interest in improvisation, transformation of sound, and space. Many of his works are made in collaboration with other artists from a range of media, and explore a range of contexts beyond the concert hall, often using interactive technology. He teaches composition and is Director of the Electroacoustic Studios at the Royal Conservatoire of Scotland in Glasgow, where he was made Fellow of the Royal Conservatoire in 2012. 